\title{
Issues in Higher Education: Analysis of 2017 Global Knowledge Index Data and Lessons Learned
}

\author{
Ali Ibrahim ${ }^{1}$ \\ ${ }^{1}$ College of Education, United Arab Emirates University, Al Ain, United Arab Emirates \\ Correspondence: Ali Ibrahim, College of Education, United Arab Emirates University, Al Ain 15551, United \\ Arab Emirates. Tel: 971-50-660-3448. E-mail: ali_saidebrahim@uaeu.ac.ae
}

Received: August 22, 2019

Accepted: December 9, 2019 Online Published: January 2, 2020

doi:10.5539/hes.v10n1p91

URL: https://doi.org/10.5539/hes.v10n1p91

\begin{abstract}
Despite considerable efforts to increase the quality of Higher Education (HE) in many countries, the absence of a methodology to guide scholars and policymakers to assess its quality has been a barrier. In 2017, the United Nations Development Program (UNDP) and Mohamad bin Rashid Al Maktoum Knowledge Foundation (MBRF) launched the Global Knowledge Index (GKI), a tool by which data from 131 countries were collected for seven sectors - one of which was HE. In this paper, an analysis of the HE index data is introduced. Then, three key issues which emerged from data are discussed. The first issue is HE efficiency, which is measured by comparing the indexes of HE inputs and outputs. The second issue is the enabling environment factors that might support or limit the growth of HE. The third issue is the intricate relationship between HE, economy, and Research and Development (R\&D). The study found that HE efficiency is declining globally except in a few areas. A strong positive relationship was found between the enabling environment and variables of political stability and government effectiveness and HE's ability of knowledge production. Furthermore, strong relationships were found between HE outputs, economy, and R\&D respectively. The study concludes with future directions for increasing the quality of $\mathrm{HE}$.
\end{abstract}

Keywords: higher education, global knowledge index, quality, efficiency, enabling context, economy, R\&D

\section{Introduction}

There is no doubt that higher education (HE) has become an increasingly important sector for most countries, and assessing its quality has become a necessity. However, this assessment has been difficult to do due to absence of clear methodology. The 2017 Global Knowledge Index (GKI) (UNDP \& MBRF, 2017), which is a collaboration between the United Nations Development Program (UNDP) and the Mohamad bin Rashid Al Maktoum Knowledge Foundation (MBRF), has made it easy for countries to assess the quality of their HE as this Index provides data for 131 countries. This paper presents an analysis of the status of HE in these countries and then moves to highlight three significant issues that emerged from the analysis of available data. This paper, therefore, serves to highlight key issues which should be considered in discussion, planning and decision making of the HE sector in many countries.

It is worth noting that we do not consider HE as an independent or self-referent system, rather, we believe that HE is a dynamic and open system that affects and is affected by its context (Bertalanffy, 1969; Mason, 2008). Therefore, policymakers are advised to think about this sector in connection with the environment as it can play a key role in either supporting or deterring HE from thriving. Using such a perspective, this study attempts to explore three issues: 1) Efficiency of HE, 2) The environment as an incubator of HE, 3) The extent to which HE, Economy, and Research and Development (R\&D) are intertwined and connected. The following section briefly introduces theoretical background to these three issues.

\section{Theoretical Background}

The first issue in this study is that of HE efficiency. Efficiency is an important issue for scholars and policymakers alike. Efficiency in HE refers to the production process or the ability of HE institutions to achieve its objectives efficiently using the shortest time and with the lowest cost. In its basic definition, efficiency is defined as the relationship between inputs and outputs in a production process (Hanushek, 2015). Simple as it seems, this statement becomes more complicated when its implementation in educational institutions is 
considered, as these institutions, especially not for profit ones, do not take efficiency for granted. They are not as competitive as private enterprises. The second reason relates to issues in assessing efficiency. Although some studies refer to student achievement or graduation rates or schooling years, these factors are affected by issues which are beyond the control of HE institutions such as socio-economic status, family cultural capital, etc. Current research indicates that HE efficiency seen through the relationship between its inputs and outputs is declining (Hanushek, 2015). Some might think that HE efficiency decline can be attributed to the general quality of the education system in a certain country. In other words, efficiency might be thought to be higher in developed countries than in underdeveloped countries. Research does not support this assumption. In certain cases, the discrepancy between HE inputs and outputs in some developing countries is less than that in some developed countries, which might mean that some developing countries can maximize the return of their HE inputs more than some developed countries (Harris, 2007). The current study attempts to investigate this hypothesis through analyzing efficiency ratios of the HE index.

The second issue in this study is that of the Enabling Environment (EE) of HE. There is no doubt that the enabling environment plays a significant role in achieving the quality of HE. The term "enabling environment" refers to the external environment or the societal context, rather than the internal environment of classrooms and facilities. Studies have examined the impact of, for example, tolerance in society, awareness and political participation, or tendency to violence in their impacts on HE. These studies consider HE as an independent variable, in that they pose the question of whether more education will lead to less violence for example (Brockhoff, Krieger, \& Meierrieks, 2015; Krueger \& Maleckova, 2002). In this study, a focus of interest is the impact of the enabling environment on HE. Specifically, we paid attention to variables such as political stability and absence of violence and terrorism, government effectiveness, and the regulatory system and whether relationships exist between these variables and the functioning of HE.

The third issue presented in this paper is the intertwined relationship between HE, economy, and R\&D. The relationship between $\mathrm{HE}$ and the economy needs no more evidence, since HE is considered a main driver for innovation, creativity, and economic growth (Hanushek, 2016), increasing gross domestic production (Decker, Rice, Moore, \& Rollefson, 1997), and economic competitiveness (Habermeier, 2007). The relationship between $\mathrm{HE}$ and economy is dynamic, as a quality $\mathrm{HE}$ system is important for economic prosperity and at the same time a strong economy is a foundation for establishing and sustaining a competitive HE sector. In the 21st century, universities are not just required to establish partnerships with companies and firms to create new knowledge and applications (Kotosz, Lukovics, Molnar, \& Zuti, 2016), but they need to have an added value on the society and the sustainability of the environment (Pawłowski, 2009). In addition, HE institutions are increasingly becoming research universities and hubs for skilled knowledge workers who can transform ideas to products and services. Now, more than ever before, big corporations are convinced that they cannot depend solely on their internal research and therefore they go into partnerships with universities (Perkmann \& Salter, 2012) to benefit from talented scholars and researchers. It is expected that partnership in R\&D between HE institutions and big corporations will continue to grow. In this study, we try to test the strengths of the relationship between the three sectors using the GKI data.

\section{Study Hypotheses}

The study has three hypotheses:

a) The score of HE output in the GKI shall be smaller than that of the HE input in a given country/region, since the inputs do not efficiently transform into outputs.

b) There is a positive relationship between the score of the enabling environment in the GKI and the score of the HE index, since HE is being affected by its surrounding environment.

c) There are positive relationships between the score of HE index in the GKI and the scores of the economy index and R\&D index, since these three sectors are interconnected.

\section{HE in the Global Knowledge Index}

This study draws on the 2017 GKI data especially those of HE, economy, R\&D, and the enabling environment. The following figure presents the different components of HE index. It consists of two main pillars: inputs with three sub-pillars namely expenditure, enrolment, and human resources; and outputs with four sub-pillars namely graduation, employment after graduation, quality of universities, and student competencies. The weights of these pillars and sub-pillars are presented in the figure. 


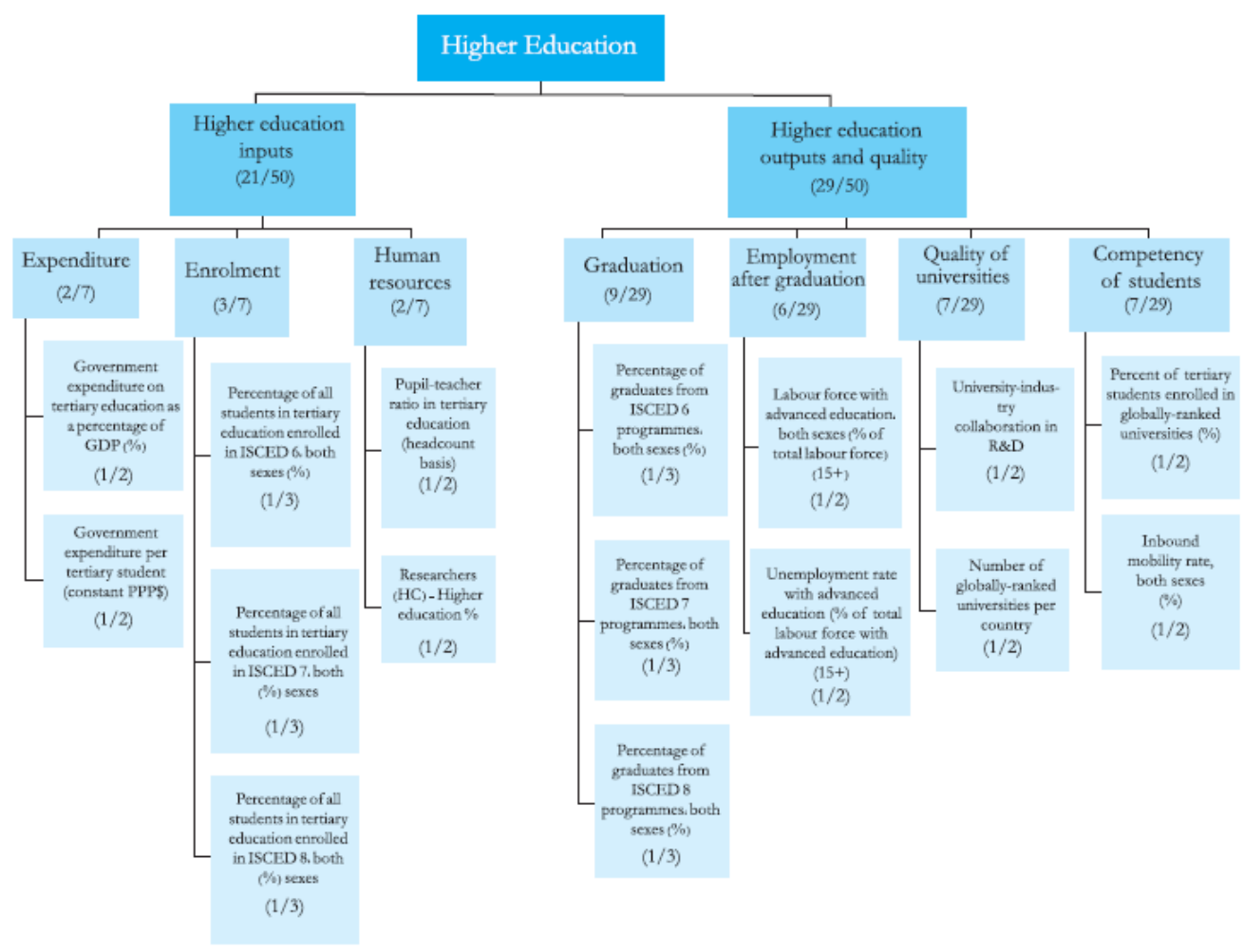

Figure 1. Structure of the Higher Education Index (Source: UNDP \& MBRF (2017). Global Knowledge Index)

\section{Study Results}

\subsection{Results of the HE Index}

The analysis of data reveals that countries of the Organization for Economic Co-operation and Development (OECD) had a score of 51.75 out of 100 points on their HE index. Sub-Saharan African countries had the least score of 29.41. The score of HE in the Arab countries was 36.95, which is below the global HE index score of 39.02. It was noticed that the scores of the output pillar were mostly less than those of the input pillar except in OECD countries and East Asia and the Pacific countries. In the Arab region, the UAE ranked first with around 50 points while Yemen ranked last with 16.2 points. The HE index scores in Mauritania and Syria were 16.8 and 21.6 respectively.

\subsection{Efficiency in $\mathrm{HE}$}

To study efficiency in HE, the scores of the outputs were divided by those of the inputs. When the difference is (1) or more, the system is considered efficient, if it is less than (1), it means that the system could not maximize on the inputs and thus it is not considered efficient. Table 1 presents the results.

Table 1. Higher education efficiency scores across regions

\begin{tabular}{lllllllll}
\hline & $\begin{array}{l}\text { Arab } \\
\text { States }\end{array}$ & OECD & $\begin{array}{l}\text { East Asia and } \\
\text { the Pacific }\end{array}$ & $\begin{array}{l}\text { Europe and } \\
\text { Central Asia }\end{array}$ & $\begin{array}{l}\text { Latin America } \\
\text { and the Caribbean }\end{array}$ & $\begin{array}{l}\text { South } \\
\text { Asia }\end{array}$ & $\begin{array}{l}\text { Sub-Saharan } \\
\text { Africa }\end{array}$ & $\begin{array}{l}\text { Global } \\
\text { Average }\end{array}$ \\
\hline N of countries & 15 & 35 & 12 & 20 & 15 & 6 & 26 & 129 \\
Efficiency ratio & 0.83 & 1.12 & 1.08 & 1.02 & 0.77 & 0.98 & 0.64 & 0.92 \\
\hline
\end{tabular}

The results indicate a decrease in the efficiency ratio of the HE sector (i.e., below 1) at the global level and in the Arab States, Latin America and the Caribbean, and Sub-Saharan Africa. Thus, it appears that the HE sector may be considered inefficient in four of the seven regions. In the Arab States, the average score did not exceed 42 on the HE inputs pillar and 33.32 on the outputs and quality pillar - a drop of more than eight points. The only exceptions were in the scores of Bahrain and Qatar; their outputs (47.17 and 49.91, respectively) were higher than their inputs (26.17 and 39.12, respectively). The highest differences between inputs and outputs were in the scores of Oman, Morocco and Tunisia. 
Overall, the results indicate that the HE sectors of most Arab States are inefficient, and that significant disparities exist between them. The efficiency ratio was higher than (1) in Bahrain (1.80) and Qatar (1.28). It was close to the desired level in Algeria (0.90) and the United Arab Emirates (0.97). Yemen ranked last on the HE index, with an average score of 16.17; and therefore it is not possible to accept the efficiency ratio in this case because the values of both pillars are very low (inputs 16.81 and outputs 15.70). Egypt, Morocco and Saudi Arabia also scored poorly on the efficiency ratio $(0.65,0.58$, and 0.72 respectively). The efficiency ratios of Mauritania, Oman and Tunisia were all less than 0.50 . Table 2 presents the results.

Table 2. Scores of Arab States on the efficiency ratio

\begin{tabular}{lllll}
\hline Country & Higher Education Index & Inputs & Outputs & Efficiency ratio \\
\hline Algeria & 40.14 & 42.6 & 38.4 & 0.90 \\
Bahrain & 38.32 & 26.2 & 47.1 & 1.80 \\
Egypt & 42.10 & 52.9 & 34.3 & 0.65 \\
Jordan & 47.64 & 53.1 & 43.7 & 0.82 \\
Kuwait & 40.15 & 43.7 & 37.6 & 0.86 \\
Lebanon & 42.52 & 47.9 & 38.6 & 0.81 \\
Mauritania & 16.76 & 24.8 & 11.0 & 0.44 \\
Morocco & 38.74 & 51.4 & 29.6 & 0.58 \\
Oman & 34.39 & 48.9 & 23.9 & 0.49 \\
Qatar & 45.38 & 39.1 & 49.9 & 1.28 \\
Saudi Arabia & 40.30 & 48 & 34.7 & 0.72 \\
Syrian Arab Republic & 21.64 & 25 & 19.2 & 0.77 \\
Tunisia & 40.05 & 58.4 & 26.8 & 0.46 \\
United Arab Emirates & 50.01 & 51 & 49.3 & 0.97 \\
Yemen & 16.17 & 16.8 & 15.7 & 0.93 \\
Arab States & 36.95 & 42 & 33.3 & 0.83 \\
\hline
\end{tabular}

Based on HE data from the GKI, we found that HE high efficiency in Bahrain, Qatar and the United Arab Emirates was due to their high scores on two sub-pillars of higher education outputs and quality, namely: competency of students and employment after graduation. These countries scored over 80 on the sub-pillar of competency of students. Bahrain and Qatar scored 52.88 and 62.96, ranking top among the Arab States on the employment after graduation sub-pillar. This may also explain the relatively high score on system efficiency in Kuwait (0.86); it scored 83.33 on the sub-pillar of competency of students, but scored much lower (29.40) on the employment after graduation sub-pillar. In contrast, the scores of Oman, Morocco and Tunisia were low on both sub-pillars.

When comparing efficiency ratios, it is important to take into account scores of the HE inputs pillar. It is not possible to compare outputs or assess efficiency, if there are big differences in inputs among states. Rating on the basis of the inputs pillar shows two different trends:

- Two countries, Lebanon and Kuwait, have close scores in terms of inputs and efficiency, scoring 47.92 and 43.66, respectively, for inputs and 0.81 and 0.86 for efficiency.

- Some countries converge in their inputs but vary in their efficiency. Examples include Tunisia and the United Arab Emirates (58.37 and 50.98, respectively, in inputs versus 0.46 and 0.97 in efficiency), Saudi Arabia and Oman (47.98 and 48.94, respectively, in inputs versus 0.72 and 0.49 in efficiency), and Jordan and Egypt (53.12 and 52.86, respectively, in inputs versus 0.82 and 0.65 in efficiency).

This confirms the differences between the Arab States in terms of their ability to utilize their inputs and maximize their returns. The experiences of countries that have succeeded in achieving the highest degree of efficiency should be highlighted in order to learn from them.

\section{$5.3 \mathrm{HE}$ and the Enabling Environment}

It should be noted that all relationships reported in this study are significant at $\alpha=0.05$. The results of this study indicate that there is a positive relationship between HE index and the enabling environment index (See Figure 2). A trend was noticed that the scores of enabling environment were always higher than those of the HE index and that the scores for the sub-pillar "Policies and Institutions" and the scores of the HE index rose together in most world regions such as the OECD, where these values were 77.57 and 51.75 respectively. They also declined together, as shown in South Asia (45.11 and 30.90) and Sub-Saharan Africa (47.22 and 29.41). 


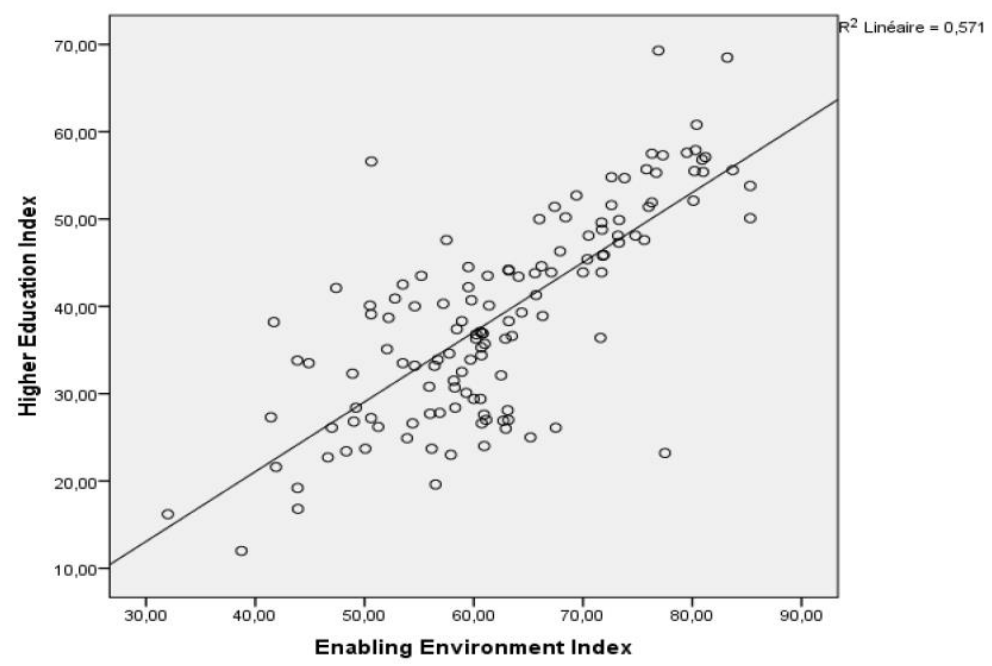

Figure 2. Correlation between enabling environment index and HE index - World

Analysis of correlation was conducted between HE index pillars (referred to as 'p') and some of its variables (referred to as ' $v$ ') with the enabling environment index and some of its variables. Table 3 presents the results.

Table 3. HE index and Enabling Environment index correlations

\begin{tabular}{|c|c|c|c|c|c|c|}
\hline Correlation & $\begin{array}{l}\text { Enabling } \\
\text { Environment } \\
\text { Index }\end{array}$ & $\begin{array}{l}\text { Policies } \\
\text { and } \\
\text { Institutions } \\
\text { (p) } \\
\end{array}$ & $\begin{array}{l}\text { Political stability } \\
\text { and absence of } \\
\text { violence and } \\
\text { terrorism (v) }\end{array}$ & $\begin{array}{l}\text { Government } \\
\text { effectiveness (v) }\end{array}$ & $\begin{array}{l}\text { Judicial } \\
\text { independence } \\
\text { (v) }\end{array}$ & $\begin{array}{l}\text { Regulatory } \\
\text { quality (v) }\end{array}$ \\
\hline HE Index & 0.80 & 0.78 & 0.56 & 0.84 & 0.66 & 0.79 \\
\hline HE inputs (p) & 0.54 & 0.59 & 0.51 & 0.59 & 0.43 & 0.52 \\
\hline HE outputs (p) & 0.76 & 0.70 & 0.45 & 0.78 & 0.63 & 0.76 \\
\hline Expenditure (v) & 0.40 & 0.47 & 0.38 & 0.46 & 0.42 & 0.39 \\
\hline $\begin{array}{l}\text { Employment after } \\
\text { graduation }(\mathrm{v})\end{array}$ & 0.78 & 0.63 & 0.52 & 0.69 & 0.45 & 0.69 \\
\hline
\end{tabular}

The results indicate a strong positive relationship $(r=0.80)$ between HE index and EE index worldwide, and a strong positive relationship between HE index and the EE index pillar of Policies and Institutions $(r=0.78)$, which means that the hypothesis of the correlation is accepted. The variable of government effectiveness had the strongest correlation $(\mathrm{r}=0.84)$ with the HE index. The results of world regions confirm these conclusions, as the correlations between HE index and EE index ranged between moderate and strong.

In the Arab States, the results also supported the acceptance of the hypothesis in that HE index and EE index were positively and strongly correlated $(r=0.80)$. However, a note should be taken that the EE index does not highly correlate with HE inputs. On analyzing the means of Arab States, we found that the values of the HE inputs were significantly low such as in Yemen (16.8), Mauritania (24.8), Saudi Arabia (25), and Bahrain (26.2). This might have caused a decrease in the HE inputs of the region. Absence of data for eight countries and the low values of expenditure in countries such as Mauritania (9.7), Lebanon (13.6), and Morocco (25.1) might have affected the correlation between EE index and expenditure. However, this does not negate the strong relationship between EE index and HE index, demonstrating that the more positive/conducive an enabling environment is in a particular country, especially in factors such as government effectiveness, the higher the HE index will become. Figure 3 presents the results of the Arab States. 


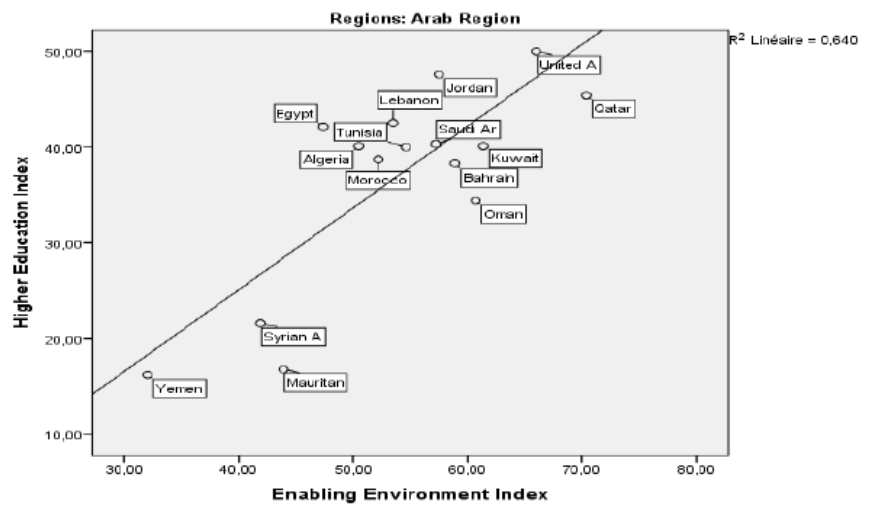

Figure 3. Correlation between HE index and EE index - Arab States

\subsection{HE Index, Economy Index, and $R \& D$ Index Correlations}

This study aimed to assess the relationships between HE index, economy index, and R\&D index. The results indicate that the OECD countries had the highest HE index (51.75) and their economy index score was also the highest (54.85). The results also indicate that the lowest score for HE index was that of the Sub-Saharan African countries (29.41) and their economy index was the lowest among all regions (36.61). This means that the two indexes arise and decline together, which might mean that a correlation between them does exist. In order to be certain of this observation, a test of correlation was performed among HE index, its inputs and outputs pillars and the economy index and the creative economy pillar and some variables such as technology exports, advanced technology, entrepreneurship, and skilled workers. Table 4 presents the results.

Table 4. Correlations between HE index and Economy index

\begin{tabular}{|c|c|c|c|c|c|c|}
\hline Correlations & $\begin{array}{l}\text { Economy } \\
\text { index }\end{array}$ & $\begin{array}{l}\text { Creative } \\
\text { economy } \\
\text { (p) }\end{array}$ & $\begin{array}{l}\text { High } \\
\text { technology } \\
\text { exports (v) } \\
\end{array}$ & $\begin{array}{l}\text { Availability of } \\
\text { advanced } \\
\text { technology (v) }\end{array}$ & $\begin{array}{l}\text { Percentage of } \\
\text { skilled } \\
\text { workers (v) }\end{array}$ & $\begin{array}{l}\text { Global } \\
\text { entrepreneurship } \\
\text { index (v) }\end{array}$ \\
\hline HE index & 0.80 & 0.60 & 0.46 & 0.79 & 0.82 & 0.83 \\
\hline HE inputs (p) & 0.51 & 0.30 & 0.26 & 0.53 & 0.56 & 0.55 \\
\hline HE outputs (p) & 0.77 & 0.62 & 0.48 & 0.75 & 0.78 & 0.79 \\
\hline Quality of universities (v) & 0.70 & 0.70 & 0.53 & 0.72 & 0.63 & 0.76 \\
\hline $\begin{array}{l}\text { University-industry } \\
\text { collaboration (v) }\end{array}$ & 0.72 & 0.56 & 0.50 & 0.50 & 0.59 & 0.75 \\
\hline
\end{tabular}

As the results indicate, there is a strong positive relationship between the HE index and the economy index $(\mathrm{r}=$ 0.80). There is also a moderate relationship with the sub-pillar of creative economy. We can notice also that the relationship between the economy index and HE output is stronger $(r=0.77)$ than the relationship with the HE inputs $(r=0.51)$. There is also a strong correlation between entrepreneurship and the HE index and HE outputs pillar, and the variables of quality of universities, and university-industry partnership. The same can be said about the variable of skilled workers. An analysis of world regions was done to confirm the results. The relationship between HE index and economy was strongest in East Asia $(r=0.90)$, and between economy index and $\mathrm{HE}$ outputs $(\mathrm{r}=0.93)$. In addition, availability of advanced technology and entrepreneurship are highly correlated with HE index.

To assess the relationship between HE index and R\&D index, correlational analyses were performed. In addition, correlation analyses were conducted between HE inputs, outputs, and some HE related variables with R\&D index and R\&D outputs sub-pillar and some of its variables, and the variables of the number of researchers in the labor force, and percentages of graduates in different scientific specializations. Strong positive relationships were found among these indexes, pillars, sub-pillars, and variables. The correlation between HE index and R\&D index was strong $(r=0.89)$. There was also a strong positive relationship between $R \& D$ outputs sub-pillar and the variable of quality of scientific research institutions with HE outputs and the quality of universities sub-pillar. There was also a strong positive relationship between HE outputs and university industry collaboration and the number of internationally ranked universities. In contrast, the relationship between HE inputs and R\&D index was weak $(r=0.46)$. Table 5 summarizes the results. 
Table 5. Correlations between HE index and R\&D index - World

\begin{tabular}{|c|c|c|c|c|c|c|c|}
\hline \multicolumn{8}{|c|}{ HE index, pillars, sub-pillars and some variables } \\
\hline \multirow{6}{*}{ 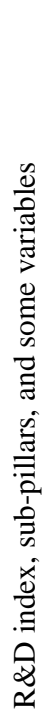 } & & $\begin{array}{l}\text { HE } \\
\text { index }\end{array}$ & $\begin{array}{l}\mathrm{He} \\
\text { inputs } \\
\text { (p) }\end{array}$ & $\begin{array}{l}\mathrm{He} \\
\text { outputs } \\
\text { (p) }\end{array}$ & $\begin{array}{l}\text { Quality of } \\
\text { universities } \\
\text { (v) }\end{array}$ & $\begin{array}{l}\text { University-industry } \\
\text { collaboration in R\&D (v) }\end{array}$ & $\begin{array}{l}\text { Number of } \\
\text { internationally ranked } \\
\text { universities }(\mathrm{v})\end{array}$ \\
\hline & R\&D index & 0.89 & 0.46 & 0.75 & 0.81 & 0.77 & 0.72 \\
\hline & R\&D outputs & 0.76 & 0.44 & 0.75 & 0.83 & 0.80 & 0.74 \\
\hline & $\begin{array}{l}\% \text { of } \\
\text { researcher in } \\
\text { labor } \\
\text { force }(\mathrm{v})\end{array}$ & 0.79 & 0.62 & 0.70 & 0.69 & 0.66 & 0.60 \\
\hline & $\begin{array}{l}\% \text { of } \\
\text { graduates in } \\
\text { scientific fields } \\
\text { (v) }\end{array}$ & 0.06 & 0.05 & 0.05 & 0.08 & -0.05 & 0.15 \\
\hline & $\begin{array}{l}\text { Quality of } \\
\text { research } \\
\text { institutions (v) }\end{array}$ & 0.84 & 0.47 & 0.84 & 0.85 & 0.88 & 0.73 \\
\hline
\end{tabular}

Analysis of different regions of the world reveals that there is a moderate to strong positive relationship between the HE index and R\&D index. This relationship becomes stronger when correlating between R\&D index and HE outputs; it was strongest in East Asia and the Pacific countries $(r=0.86)$, then in Arab States $(r=0.72)$. The analysis of data also confirmed a relationship between the sub-pillar of R\&D outputs and HE outputs and the variable of university-industry collaboration. In East Asia and the Pacific these correlations amounted to $(\mathrm{r}=$ 0.93 and $r=0.86$ ) respectively. The correlation between the quality of research institutions and HE outputs was strong in the Arab States $(r=0.84)$ and is the strongest in East Asia and the Pacific $(r=0.92)$. The results permit the acceptance of the hypothesis that there is an interconnection between HE index and R\&D index.

In the Arab region, we notice that $R \& D$ index scores were among the lowest. For example, although the economy index and HE index in the UAE was above 43, R\&D index was below 29. The same can be said about Jordan; while its economy index was 48.2 and HE index was 46.7, its R\&D index was very low (19.2). That said, a strong relationship between R\&D index and HE index in the Arab States was obtained (as shown in Figure 4). Therefore, Arab States should consider improving the outputs of R\&D as they correlate with HE index.



Figure 4. Correlations between HE index and R\&D index - Arab States 


\section{Conclusion}

The first issue this study attempted to investigate is that the HE inputs do not translate into outputs as efficiently as we desire. The results of this study confirms this hypothesis. The reasons might be that the processes of HE are complex and difficult to measure, or that there are some intervening and uncontrollable factors, which create gaps during the transformational processes. Another reason might be that some countries pay more attention to quantity than quality in higher education. For example, they care about the number of admitted students more than the quality of learning provided to them. This concern has made international organizations to call on countries to shift their emphasis from being concerned with providing access to higher education to providing quality learning experiences to students (World Bank, 2018). However, demographic and economic reasons prohibit many countries from making such a shift in focus. Adding to the complexity of the issue is the belief by people in some countries, especially post-socialist ones, that higher education is a service that should be funded by the government (Williams, 2016).

Furthermore, many governments which sponsor HE institutions face challenges of increased demand and declining government funds. HE institutions supported by these governments often lack the perspective of a global transformation toward a competitive higher education sector and therefore might retain outdated modes of running the institutions in absence of the imperatives of the market and international competitiveness. The HE private sector, in contrast, keeps an eye on these factors and draws on them for continuous improvement and providing quality services. Regardless of the reason for a declining efficiency in HE institutions when measuring outputs to inputs, it is imperative that policymakers investigate such an issue and find ways to increase efficiency.

The other idea explored in this study is that HE is inseparable from its societal context, as HE institutions work in an enabling environment which should have an acceptable level of political stability, rule of law, absence of violence and terrorism, and government effectiveness. These factors are needed for HE to thrive and create knowledge. The results of this study confirms this conclusion. One clear example of this is that countries suffering from political instability and government ineffectiveness (such as in Yemen and Syria) had the lowest scores on the HE index. Therefore, governments should make certain that these environmental factors do exist at an acceptable level, since their decline might mean that HE institutions, and other institutions and sectors, will not prosper.

This study also explored the idea that HE should not be thought of without considering its relationship to economy and R\&D. The study confirmed the interconnectedness of this multi-faceted relationship and the relationships among these three sectors in general and among specific pillars and variables that correlate significantly with HE sector. Therefore, it is important that policymakers think holistically about these sectors and target intersecting pillars, sub-pillars, and variables and improve them such as entrepreneurship, advanced technology, and quality of scientific research institutions.

\section{References}

Bertalanffy, L.V. (1969). General system theory: Foundations, development, applications. New York: George Braziller.

Brockhoff, S., Krieger, T., \& Meierrieks, D., (2015). Great expectations and hard times: The (nontrivial) impact of education on domestic terrorism. Journal of Conflict Resolution, 59(7), 1186-1215. https://doi.org/10.1177/0022002713520589

Decker, P. T., Rice, K. J., Moore, M. T., \& Rollefson, M. R. (1997). Education and the Economy: An Indicators Report. Washington, D. C.: National Center for Education Statistics.

Habermeier, H. U. (2007). Education and economy - an analysis of statistical data. Journal of Materials Education, 29(1-2), 55-70.

Hanushek, E. A. (2015). Economics of Education. In N. J. Smelser \& P. B. Baltes (Eds.). International Encyclopedia of the Social \& Behavioral Sciences (Edition 2, Vol. 7, pp. 149-157). New York: Elsevier. https://doi.org/10.1016/B978-0-08-097086-8.92052-X

Hanushek, E. A. (2016). Will more higher education improve economic growth? Oxford Review of Economic Policy, 32(4), 538-552. https://doi.org/10.1093/oxrep/grw025

Harris, D. N. (2007). Diminishing marginal returns and the production of education: An international analysis. Education Economics, 15(1), 31-53. https://doi.org/10.1080/09645290601133894

Kotosz, B. G., Lukovics, M., Molnár, G., \& Zuti, B. (2015). How to measure the local economic impact of 
universities? Methodological overview. Regional Statistics, 5(2), 3-19. https://doi.org/10.15196/RS05201

Krueger, A. B., \& Maleckova, J. (2002). Education, poverty, political violence and terrorism: Is there a causal connection? (No. w9074). National Bureau of Economic Research. https://doi.org/10.3386/w9074

Mason, M. (2008). Complexity theory and the philosophy of education. Educational philosophy and theory, 40(1), 4-18. https://doi.org/10.1111/j.1469-5812.2007.00412.x

Pawłowski, K. (2009). The 'fourth generation university' as a creator of the local and regional development. Higher Education in Europe, 34(1), 51-64. https://doi.org/10.1080/03797720902747017

Perkmann, M., \& Salter, A. (2012). How to create productive partnerships with universities. MIT Sloan Management Review, 53(4), 79-88.

The World Bank Group, 2018. Higher Education. Retrieved from http://www.worldbank.org/en/topic/tertiaryeducation

UNDP \& MBRF (2017). Global Knowledge Index Data Download. Retrieved from http://knowledge4all.com/DataDownload.aspx?language=en

Williams, G. (2016). Higher education: Public good or private commodity? London Review of Education, 14(1), 131-142. https://doi.org/10.18546/LRE.14.1.12

\section{Copyrights}

Copyright for this article is retained by the author(s), with first publication rights granted to the journal.

This is an open-access article distributed under the terms and conditions of the Creative Commons Attribution license (http://creativecommons.org/licenses/by/4.0/). 